Annual Meeting
11472017 Annual Meeting and Exhibition Review

1148 APSA Awards

1152 Teaching Civic Engagement Across the Disciplines
11532017 Ralph Bunche Scholars Present iPosters

1154 Graduate Students and Scholars Funded

11562017 APSA

Organized Section Awards Presented

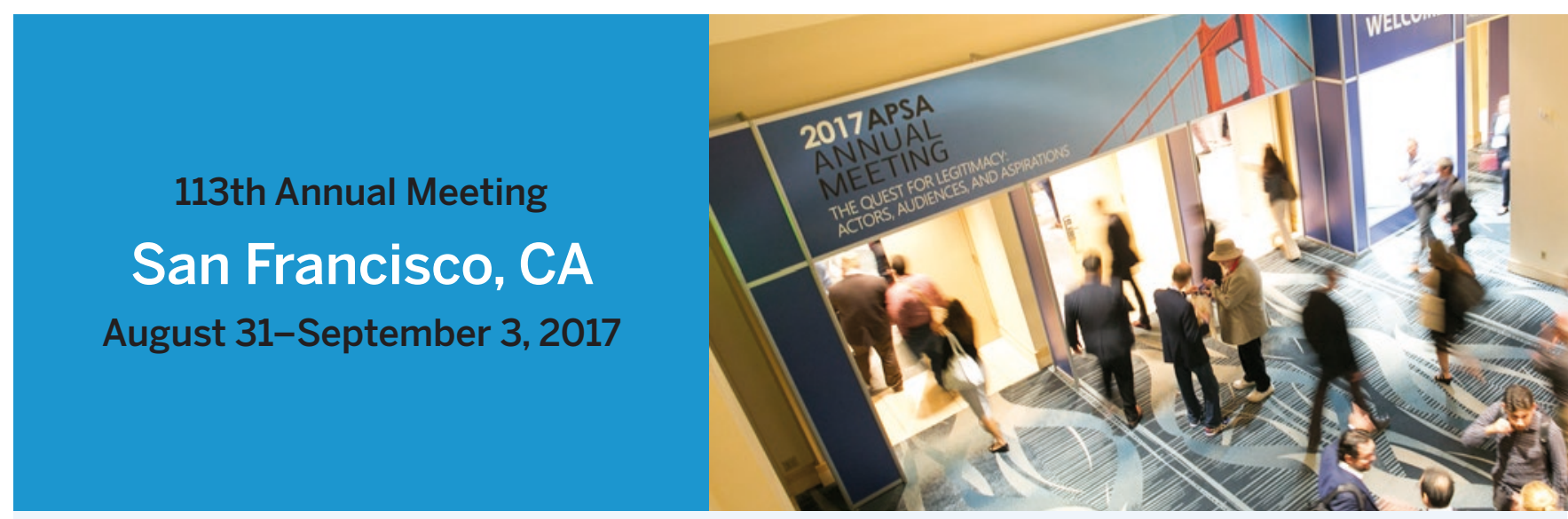

\title{
Annual Meeting and Exhibition Review
}

\section{Steven Rathgeb Smith, Executive Director, APSA}

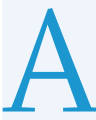

PSA welcomed nearly 6,0oo political scientists from around the world to San Francisco for the 113th Annual Meeting August 31-September 3. At the meeting, APSA colleagues, including faculty and students, policy makers, journalists, and citizens interested in political science gathered for four days of panels, roundtables, and special events for scholars to present, learn, and network at the largest political science conference. Attendees explored an exciting program, which brought together more than 1,200 sessions on the latest scholarship in political science focused on the 2017 theme "The Quest for Legitimacy: Actors, Audiences, and Aspirations." The 2017 Annual Meeting Program Chairs, Amaney A. Jamal, Princeton University and Susan Hyde, University of California, Berkeley, organized the meeting around diverse approaches to all subdisciplines of political science.

Preconvention activities began on Wednesday, August 30, with registration and 16 short courses and workshops. These programs allowed for a deep dive in a focused environment. They were professional-development focused, subfield specific, or thematically of the same spirit or accomplishing the same knowledge-sharing and learning goals. The day concluded with the APSA Awards Ceremony, where the association celebrated and recognized 29 individuals for notable career and research achievements.

Thursday, August 31, marked the official beginning of the meeting and featured two breaking news sessions: "Policy Shifts from Obama to Trump: Discussing the Current US Legislative Agenda" and "The Legitimacy of Elections: Russia, Fraud, and Public Confidence in the Electoral Process," as well as panels and roundtable discussions. The first day of the meeting culminated with a keynote by University of
California President Janet Napolitano and a presidential address by APSA President David Lake, University of California, San Diego, on "International Legitimacy Lost: Rule and Resistance When America Is First." Both sessions were followed by the Opening Reception. During the sessions on Friday and Saturday, attendees enjoyed a variety of division, related group, and professional development panels.

Attendees also networked throughout the weekend, attending a variety of evening events like the International Attendee Reception, the Reception Honoring Women of Color in the Profession, the Donor Reception, the Graduate Student Happy Hour, the RBSI/Minority Fellow Program Reception, university alumni receptions, and a variety of APSA Organized Section annual meetings and receptions. Many attendees visited eJobs Interview Services, which provided onsite interview space for APSA members and university departments. Around $75 \%$ attendees used a variety of "green" options for navigating the conference content, whether it was the interactive online program, the mobile app, or the ePDF program.

The 2017 meeting also continued use of APSA's electronic, multimedia iPosters in the Exhibit Hall. With interactive features such as the ability to enlarge graphics and images, as well as include video and audio clips, the iPosters provided a much more interactive experience for poster authors and attendees alike. In addition to viewing posters onsite in San Francisco, APSA attendees and members may view 2017 Annual Meeting posters pre- and postconference via an online gallery, providing a much wider window of engagement for authors to receive feedback as well as a convenient way for APSA colleagues to share feedback or find opportunities for collaboration, all while eliminating high printing costs and travel risks for poster authors. 
The packed APSA exhibit hall featured 6o organizations including political science publishers, news and media outlets, educational technology companies, research organizations, foundations, and nonprofit organizations. A robust variety of sponsored social events on the exhibit show floor also provided valuable opportunities for networking outside the sessions, including the Headshot Lounge, sponsored by Pearson, which allowed APSA attendees to have new professional photographs taken. As always, the APSA Lounge offered a comfortable space where attendees could meet to discuss issues of mutual interest.

APSA would also like to express our deep appreciation to our corporate sponsors: Cambridge University Press, Pearson, Rowman \& Littlefield, Lynne Rienner Publishers, Pi Sigma Alpha, SAGE, and YouGov.

We are very much looking forward to our next annual meeting in Boston, August 30-September 2, 2018. See you there!

\title{
APSA Awards
}

\begin{abstract}
A
$t$ the 2017 APSA Awards Ceremony, the association recognized an exceptional group of diverse individuals for their contributions to political science. The ceremony was held on Wednesday, August 30, 2017 at the Westin St. Francis in San Francisco. This year APSA gave 26 awards recognizing outstanding achievement in the profession in the categories of dissertation awards, paper and article awards, book awards, and career awards. A complete list of the awards is included in the Gazette section of this issue, and a listing of the Organized Section awards is provided later in this section.
\end{abstract}

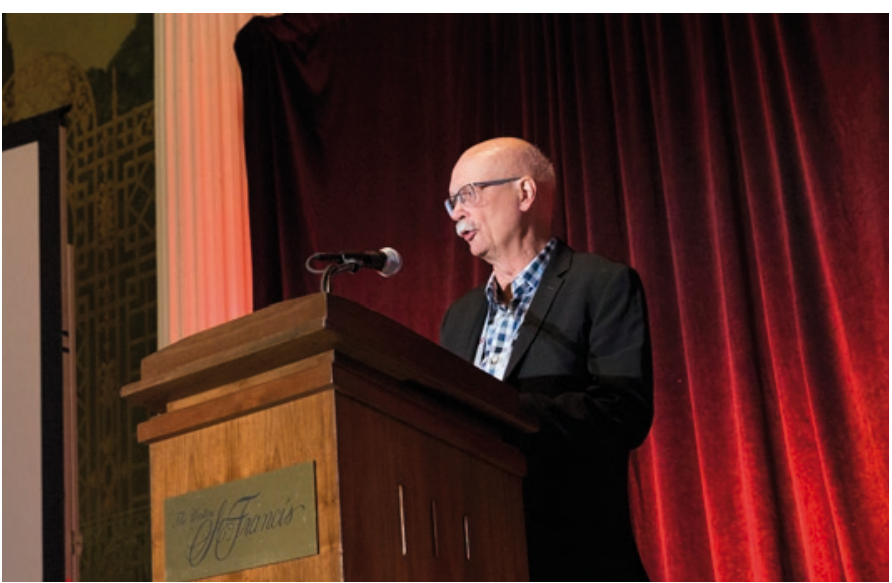

Outgoing APSA President, David Lake, University of California, San Diego, kicks off the awards ceremony.

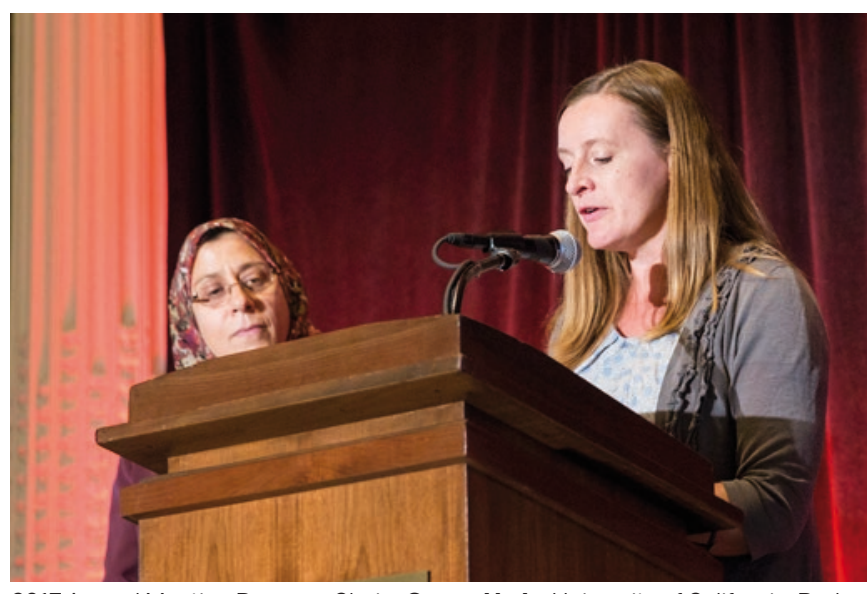

2017 Annual Meeting Program Chairs Susan Hyde, University of California, Berkeley, and Amaney A. Jamal, Princeton University, recognize each of the recipients.

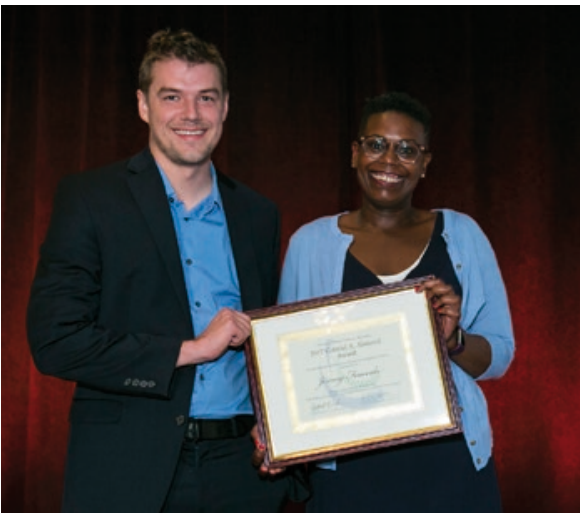

Jeremy Ferwerda, Massachusetts Institute of Technology, receives the Gabriel A. Almond Award from Kimuli Kasara, Columbia University. It is given annually for best dissertation in the field of comparative politics.

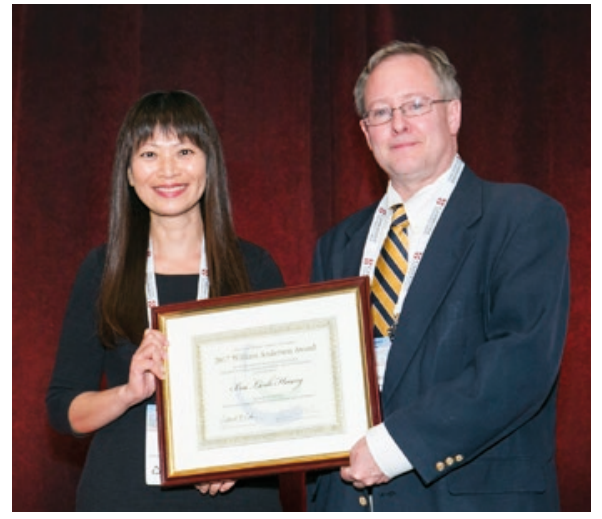

Bai Linh Hoang, University of Michigan, receives the William Anderson Award from Michael Hail, Morehead State University. It is given annually for best dissertation in the general field of federalism or intergovernmental relations, state, and local politics.

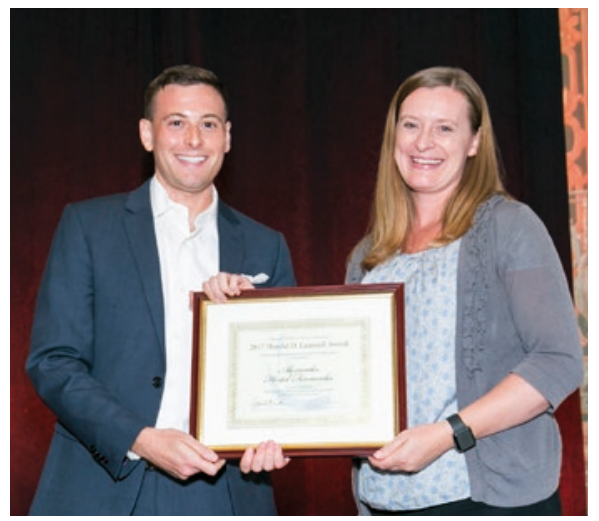

Alexander Hertel-Fernandez, Harvard University, receives the Harold D. Lasswell Award from Susan Hyde, University of California, Berkeley. It is given annually for best dissertation in the field of public policy and is supported by the Policy Studies Organization. 